\title{
Analysing the "Response" to the Tibetan Language Under RPS Model in Language Ecology
}

\author{
Xuewen Duan ${ }^{1, \mathrm{a}}$ \\ ${ }^{1}$ School of Languages and Cultures, University of Queensland, Brisbane, Australia \\ ${ }^{a}$ Email: xuewen.duan@uq.net.au
}

\begin{abstract}
This study explores Tibetan's language ecology. The study applies the first-grade indicators of the "response" under a Press-State-Response (PSR) model to assess the ecology of Tibetan language used in Tibetan-inhabited areas of China. The study collects data from well-documented research and the author's empirical experiences with the Tibetan language. The study suggests that education, the (people and government's) attitudes towards the Tibetan language, and speakers' language competence cannot effectively support the language ecology of Tibetan. The study reflects the whole picture of the minority languages in China and illuminates the direction for future language maintenance improvement.
\end{abstract}

Keywords: Tibetan Language, Language Ecology, PSR Model, Ecolinguistics

\section{INTRODUCTION}

Sustainable development has gained continuous attention in the $21 \mathrm{st}$ century. In particular, the sustainability of culture, the environment, and the economy seem to be major concerns for many researchers in the sustainable development field. Alongside these aspects, linguistic sustainability requires immediate attention as well. According to data from Moseley [1], at least $43 \%$ of languages spoken in the world are currently in an endangered state. A great loss of proficient speakers in many of these languages could cause a severe damage to both valuable cultures and ethnic identities within these communities. The People's Republic of China (PRC) is a country with a large number of endangered languages. In fact, more than half of China's languages are endangered to various degrees [1]. Many languages used by ethnic minority groups in China have become endangered or have been at risk of becoming endangered.

The Tibetan language is one of the minority languages which is losing its vitality and sustainability. A limited amount of studies have specifically paid attention to language ecology in Tibet [2][3][4][5][6]. The previous studies have rarely analysed the ecology of Tibetan using ecolinguistic theories or framework. This study will partially apply a Press-State-Response (PSR) model to look at the language ecology of Tibetan on a macro level. The status quo of Tibetan languages can reflect the overall linguistic sustainability of minority languages in China. It is also expected that this brief study will somehow raise the world's awareness of language endangerment.

\section{RESEARCH CONTEXT}

This study will assess the language ecology of Tibetan used in Tibet. In this study, Tibetan refers to all the Tibetic languages which are realised and described as "Tibetan", while Tibet refers to Tibetan-inhabited areas of China. Tournadre pointed out that Tibetan is not a single language, but rather, clusters of historically and linguistically related languages that are frequently realised as a single language "Tibetan" [7]. Tibetan is the official language of Tibet, and is primarily used by the Tibetan ethnic group that live in Chinese provincial administrative regions such as Tibet Autonomous Region, Yunnan, Sichuan, Qinghai, Gansu, and other Asian countries such as Bhutan, Nepal, India and Pakistan. Tibetan is a critical asset to China's communication and culture system. It is essential to understand the status quo of Tibetan from an ecolinguistic perspective.

\subsection{A Brief Overview of Ecolinguistics}

It was not until the second half of the 20th century did a group of linguists start to study language ecology systematically. As a pioneer of ecolinguistics, Haugen called for attention to what he called "the ecology of language" since linguists had been obsessed with theoretical linguistics [8]. Haugen defined language 
ecology as the study of the interaction between the language and its environment. He stressed that the "true environment" in language ecology study refers to the society which uses "a language as one of its code" rather than a "referential world to which language provides an index" [8]. The ecology metaphor can help understand the relationship between language and the environment. Haugen's metaphor suggested that certain analogues exist between language and biological organisms -- like biologically living organisms, language could be born and die [8]. Haugen's study has inspired many scholars to explore the ecology of languages, and to associate linguistics with the economy, the natural environment, culture and politics.

However, some aspects of Haugen's metaphoric approach are problematic. Although analogues exist between language and natural ecology, many uncertainties are still embedded in this relatively new discipline sprouted on the basis of metaphor. While agreeing with Haugen's ecology metaphor, Denison posed the question of whether the preservation of linguistics species should be regarded as on a par with that of natural species. Denison stated that, unlike clearly bounded natural species within the natural ecology, language boundaries are vague and interpenetrated [9]. The fuzzy boundaries of language can bring potential problems when it comes to assessing the ecology of languages in their environments. Another uncertainty, according to Garner, is caused by the ontological status of interaction between language and its environment [10]. It is unsure whether the interaction process is literal, since language (metaphorically the organism) is a metaphorical entity, whereas the environment is a literal entity. There is no evidence that suggests interaction amongst languages and their environments resemble organisms and the natural environment in the biological ecology system. Furthermore, metaphors are not enough when it comes to language revitalisation, revival, or reversal.

Halliday led a non-metaphoric strain of ecolinguistics. Halliday claimed that language has the ability to construe the world instead of passively reflecting it. Therefore, language has a role in environmental issues and changes [11]. Halliday urged linguists to be more aware of social and environmental issues. He notified the linguists that it was their social responsibility to better the natural environment through their strategic use of language. Hallidayan approach encouraged the discourse analysis. Alexander and Stibbe distinguished between "the analysis of ecological discourse" and "the ecological analysis of discourse" [12]. They believe that ecolinguistics study should not be limited to discourse concerning biological ecology but should extend to all types of discourse. This is because that all discourse impacts human behaviour while biological ecology is largely shaped by human behaviour. Stibbe proposed the concept of "story", which refers to a cognitive structure that impacts how people perceive the world. Stibbe argued that ecolinguistics studies essentially revealed the stories that shape the society and people's life [13]. The stories can bring both constructive and destructive changes to the ecology. The Hallidayan approach linked linguistics to contemporary social issues and the biological ecosystem. Ecolinguistics has therefore become an interdisciplinary study of ecology and linguistics.

The internationally influential studies in ecolinguistics are somewhat western-centred. Chen's comprehensive content analysis in ecolinguistics pointed out that most ecolinguistics leading proponents were based in North America and Europe [14]. The amount of non-English and non-western studies on ecolinguistics is relatively limited compared to the English ones. The inconsistency in indexation systems across the globe added to the difficulty of integrating the contributions of ecolinguistics scholars located in different regions. Hence it is critical for more non-western scholars to study language ecology, and integrate these internationally influential approaches within their own studies. It is also necessary to study non-dominant languages in different regions across the world to examine and improve current ecolinguistics approaches.

\subsection{Concerns about Tibet's Language Ecology}

This paper categorises major concerns about Tibet's language ecology into two groups. Firstly, scholars have expressed their worries about the declining linguistic diversity in Tibet [2][3][5]. An incredibly common misconception is that Tibet is a linguistically homogeneous region [5]. These misconceptions, together with inadequate documentation of Tibetic languages, have impeded the maintenance of language diversity in Tibet. Wendel and Heinrich believed that a negative relationship exists between economic development and linguistic diversity [15]. In pursuing a better economy, linguistic diversity in Tibet may continue to decline.

Other apprehensions concern the subordinate status of Tibetan as a minority language. Under China's bi-lingual and diglossia system, minority languages were generally at a disadvantage compared with Mandarin. Posner pointed out a common fear amongst minority language speakers: bilingualism and diglossia could lead to language shift, attrition, and extinction [16]. Furthermore, the dominant status of Mandarin has contributed to the vulnerability of Tibetan, triggering a series of statusrelated concerns (i.e. the appropriateness of language policies, the effectiveness of linguistic rights protection, the loss of motivation to learn Tibetan). 


\section{PSR MODEL IN LANGUAGE ECOLOGY AND METHODOLOGICAL CONCERNS}

The Press/Pressure-State-Response (PSR) model has previously been used in environmental policies and reporting. This systematic model, developed by the Organisation for Economic Co-operation and Development (OCED), assesses the pressure on the environment exerted by human activities (pressure), the conditions of the environment and natural resources under the impact of human activities (state), and how the society responds to these changes through social policies, and through changes in awareness and behaviour (response) [17]. Xiao and Fan, two Chinese linguists specialising in endangered and minority language maintenance, designed a PSR model in language ecology. Twelve first-grade indicators (see Table 1.) and 33 secondary indicators (see Table 2.) were developed for scaling and evaluating language ecology. Their system involves statistics and calculation based on computational models to assess the ecology of a language. The response under the model particularly assessed education, the (people and government's) attitudes towards a language, and the speakers' language competence [18]. These indicators are closely connected to the vitality and sustainability of a language.

Xiao and Fan's PSR model is a relatively updated and systematic attempt to assess language ecology. The model is direct and largely understandable. It considered the inner ecology (the phonology, grammar, lexicon, semantics, etc.) and external ecology of a language [18]. Using this PSR model (with some changes and adjustments), Pan [19] and Zou [20] studied the ecology of the Chinese language under the noticeable influence of
English penetration and new-born catchphrases in China respectively. They have acknowledged the usefulness of, and illumination brought by the PSR model. It is worthwhile introducing this Chinese-developed model to the international ecolinguistics arena.

Xiao and Fan's PSR model has its limitations. More factors are needed for the comprehensiveness of the model. For instance, the influence of language policies and language contact were not specifically included in this PSR model. The effectiveness of language policies could impact the sustainability of languages when they face undesirable language contact and other issues that affect their ecology. Similar to many other models that assess the ecology of a language, Xiao and Fan's PSR model seems to neglect the factors which contribute to the revival and revitalisation of languages. The possibility of language revival and revitalisation is worthy of being examined when looking at the ecological conditions of a language.

Due to the limited time and resources given, and the author's inability to conduct a field research in Tibet, this study will only adopt the first-grade indicators (see Table 1.) of the "response" under Xiao and Fan's PSR model (see Table 2.) to assess the language ecology of Tibetan. In particular, the study will analyse if education, attitudes towards the Tibetan language, and speakers' language competence can adequately support the language ecology of Tibetan. This study mainly collects and analyses qualitative data. Due to the limitations mentioned above, this research consists of secondary data collected from well-documented academic research in the recent 20 years and some empirical data from the author's observations and constant conversations and discussions with university students in Tibet.

Table 1. First-grade Indicators of PSR Model

\begin{tabular}{|l|l|}
\hline PSR & First-grade Indicators \\
\hline Pressure & Demography \\
\cline { 2 - 2 } & Geography \\
\cline { 2 - 2 } & Culture \\
\cline { 2 - 2 } & Economy \\
\hline State & Language Pattern \\
\cline { 2 - 2 } & Register \\
\cline { 2 - 2 } & The degree of the Language Standardisation \\
\cline { 2 - 2 } & Language Structure \\
\cline { 2 - 2 } & Language Product \\
\hline Response & Education \\
\cline { 2 - 2 } & Attitudes towards the Language \\
\cline { 2 - 2 } & Language Competence \\
\hline
\end{tabular}


Table 2. Xiao and Fan's PSR Model (in English)

\begin{tabular}{|c|c|c|}
\hline PSR & $\begin{array}{l}\text { First-grade } \\
\text { Indicators }\end{array}$ & Secondary Indicators \\
\hline \multirow{11}{*}{ Press } & \multirow{4}{*}{ Demography } & Population base of language usage \\
\hline & & The proportion of language speakers in the total population \\
\hline & & The proportion of youth speakers in the population \\
\hline & & Variation tendency of language speakers \\
\hline & \multirow{2}{*}{ Geography } & The degree of settlement of the language communities \\
\hline & & Geographical openness of language communities \\
\hline & \multirow{3}{*}{ Culture } & The stability of cultural customs and traditional rituals \\
\hline & & Traditional folk activities and the choice of words in rituals \\
\hline & & Language speakers' attitudes towards intermarriage \\
\hline & \multirow{2}{*}{ Economy } & Economic strength of language communities \\
\hline & & Types of economic industries in language communities \\
\hline \multirow{16}{*}{ State } & \multirow{2}{*}{ Language Pattern } & The prestige and influence of the adjacent language(s) \\
\hline & & Cross-border usage of language \\
\hline & \multirow{6}{*}{ Register } & Language usage within the families \\
\hline & & Language usage in daily communication \\
\hline & & Language usage in broadcast and television media \\
\hline & & Language usage in commercial activities \\
\hline & & Language usage in the administration \\
\hline & & Religious belief and its relationship with language \\
\hline & \multirow{2}{*}{$\begin{array}{c}\text { Degree of } \\
\text { Language } \\
\text { Standardisation }\end{array}$} & Dialectal differences and comprehension within the language \\
\hline & & Situation of writing system or written language usage and standard \\
\hline & \multirow{3}{*}{$\begin{array}{l}\text { Language } \\
\text { Structure }\end{array}$} & The stability of the phonetic system \\
\hline & & The stability of the lexical system \\
\hline & & The stability of the grammatical system \\
\hline & \multirow{3}{*}{$\begin{array}{l}\text { Language } \\
\text { Products }\end{array}$} & The quantity and the range of application of language teaching products \\
\hline & & The quantity and readership of cultural life language products \\
\hline & & The quantity and quality of language research products \\
\hline \multirow{6}{*}{ Response } & \multirow[t]{2}{*}{ Education } & $\begin{array}{l}\text { The quantity of primary school that uses language as classroom } \\
\text { expression }\end{array}$ \\
\hline & & The quantity of school or institution with language courses \\
\hline & \multirow{2}{*}{$\begin{array}{l}\text { Attitudes towards } \\
\text { the Language }\end{array}$} & Attitudes towards the language within the language community \\
\hline & & The tendencies of government's policies or behaviours \\
\hline & \multirow{2}{*}{$\begin{array}{l}\text { Language } \\
\text { Competence }\end{array}$} & The proportion of monolingual speakers in the language community \\
\hline & & The proportion and proficiency of bilingual or multilingual people \\
\hline
\end{tabular}

\section{ASSESSING THE "RESPONSE"}

Although China's state organs have shown some support for Tibetan [4] and China's legislature have recognised the role of minority languages [21], obstacles affecting Tibetan's language ecology persist. Different problems linger in different regions, but there are similar problems and common trends for the Tibetan language found across these areas. The "response" to Tibetan language ecology determines the future development of the Tibetan language. By looking at whether education, attitudes towards the Tibetan language, and speakers' language competence of Tibetan can help improve the language ecology effectively, prospects of Tibetan can become clearer.

\subsection{Education}

Bilingual education is a dominant education model in Tibet. Bilingual education in China provides ethnic minority groups with a major channel to integrate themselves into the mainstream of social, economic and cultural activities in a modern civil society [22]. Ideally, bilingual education can motivate the Tibetan people to learn the Tibetan language as well as Mandarin to a relatively equal extent. In that case, Tibetan and Mandarin can co-exist in a harmonious way, where promoting one language does not impede the language ecology of the other. However, Tibet's bilingual education model needs extensive improvements to achieve this harmony. The model has not proven to always be an effective channel for Tibetans' integration into mainstream social activities. The admission quotas of universities can exemplify the situation. Only a small number of Tibetan students have been admitted to the mainstream universities outside Tibet, and the proportion of Tibetan students amongst students enrolled in China's top universities is extremely limited. Tibetan students tend to complete higher education in their own regions. As a consequence, the distance between China's mainstream intellectuals and higher education systems and that of Tibet persists. 
There were top-down attempts aimed at supporting Tibetan people to enter the top universities of China. The “Inland Tibetan Class" (西藏内地班) was one important government-supporting programme amongst these attempts. Classes and schools associated with the topquality schools in coastal cities or independently founded with the government budget were offered to Tibetan people. Although the programme has successfully provided support for approximately 33,100 students between 1985 and 2006, it ultimately attracted Tibetans to learn Mandarin and attend Chinese teaching schools in order to access top-quality education [22]. Moreover, the Mandarin teaching model gradually gained dominance when Tibetan students entered the higher education system. Mandarin implies better education and more employment opportunities and is therefore associated with the strong attraction of language learning and strong sustainability. The lack of top-quality education institutes in Tibet and the disconnection between the Tibetan language and quality education contribute to the unsatisfactory effects of top-down attempts. Thus, topdown support for Tibetan language education did not seem to essentially reduce the vulnerability or boost the ecology of Tibetan in bilingual education.

The unequal distribution of resources has also affected the language ecology of Tibetan. It was, and it still is the case that many minority education institutes lack basic resources. Despite the increase in bilingual education investment and enhanced training of bilingual teachers [23], many education institutes lack dedicated and professional teachers while Tibet is still an underachiever in China's national education system. The effect of bilingual education is still unsatisfactory regardless of a growing trend of volunteer teachers teaching in rural areas and ethnic minority group inhabited areas. A shortage of electronic resources in Tibetan education has been reported. Xiao and Higgins suggested that Tibetan television programmes were less rich and diverse compared to the programmes in Mandarin [24], indicating an inadequate exposure to the Tibetan language through digital platforms. Additionally, Zhou and Jiang's research highlights that the Tibetan platform application rate of workers in 35 different work units in Tibetan-inhabited regions was only $20 \%$ [25]. Maintaining the vitality of language in a modern civil society relies heavily on electronic resources. It is critical to refine the distribution of educational resources, particularly electronic resources, to improve language ecology.

\subsection{Attitudes towards the Language}

The diglossia system in China has impacted the social status of Tibetan and Mandarin. It is commonly believed that Mandarin is closely connected with better employment opportunities and educational resources. Ko's interview with Tibetan residents disclosed that
Tibetans tend to believe learning Mandarin allows them to be more competitive [26]. Meanwhile, white-collar professions want their employees to speak fluent Mandarin, feeding into the association of Mandarin with higher prestige and more importance in employment. It is not surprising that the main instruction language in Tibet is gradually transitioning into Chinese, whereas Tibetan is taught as a language subject [27]. Tibetan therefore loses its social significance to some extent. Zhang and Pérez-Milans' research corresponds with this statement as their interviewees (Tibetan teachers) expressed how their school did not pay enough attention to Tibetan. The school relied on students' good performance in other subjects to improve their competitiveness. Teachers and students did not regard Tibetan as an important subject [28]. Some teachers even pulled students away from learning Tibetan, deeming its weak role in examination and higher education system [21]. The diglossia system pushes Mandarin to be the instruction language associated with more social importance, and Tibetan to be the daily language. Tibetan, in the diglossia system, is at the risk of losing its prestige and its attraction to speakers.

Tibetan speakers and the government have both shown efforts to support the Tibetan language. Tibetan Buddhists were the active advocators of Tibetan language maintenance. For instance, the 10th Panchen Lama urged the establishment of Tibetan language schools in Snowland Tibetan Autonomous Prefecture [28]. Furthermore, Roche and Bum found that Buddhist monasteries cooperated with influential language brokers to offer Tibetan-medium education, such as literary Tibetan classes [4]. Seeing the vulnerability of their language, Tibetan speakers have taken initiatives to form associations that allow them to protect and/or promote Tibetan. Their ethnic, cultural and religious identity also encourages Tibetans to develop these associations. The author noticed that Tibetan university students have also organised special events and societies that urge Tibetan to speak and protect Tibetan language and culture. Nevertheless, these associations and events have limited influence and are relatively small compared to state academies. Roche and Bum indicated that the grass-root institutions often have unclear goals and poor management [4]. The government was partly supportive in protecting the Tibetan language, yet its role in the bigger picture of protecting the Tibetan language remains unclear. There have been cases where the government restricted and closed grass-root language protections institutions and cases in which the state academies and councils supported corpus planning and provided digital platforms for Tibetan language communication.

Both Tibetan people and the government tend to support Standard Tibetan, yet have weaker awareness of the role of other Tibetic varieties. As mentioned earlier in this paper, many have failed to comprehend the linguistic diversity in Tibet while major resources in the Tibetan language were offered in Standard Tibetan. It was also 
reported that dialects like Hualong Tibetan were associated with negative social characteristics according to Non-Hualong Tibetan speakers [4]. This correlates with the concerns about linguistic diversity in Tibetan language ecology. In addition, the author found out during the discussion with Tibetan students that the Tibetan university students tend to speak with each others in Standard Tibetan even though they possess native or bilingual proficiency in non-standard Tibetic varieties. The students tend to associate standard Tibetan with a sense of ethnic pride while regarding the other varieties as the symbol of being undereducated. Poor documentation alongside the negative impressions against non-standard Tibetan could damage the language ecology in Tibet.

\subsection{Language Competence}

The linguistic ability of Tibetan speakers varies in Tibet. Those who started to learn Tibetan at an early age or speak Tibetan as a mother tongue doubtlessly possess better linguistic performance. Zhang et al. imply that a wide discrepancy in Tibetan language competence between Tibetan students and students from other regions in university exists due to the various extents of exposure to the Tibetan language. Yet students were all exposed to Mandarin since the beginning of their primary education [6]. This can cause a lack of strong motivation for people outside Tibet to learn Tibetan. Although most of Tibetan universities require students to learn Tibetan regardless of their ethnic backgrounds, those who learn Tibetan as a L2 find it unnecessary to reach the mastery of Tibetan. Since they can communicate with Tibetan people in Mandarin smoothly, they may have limited incentive to learn Tibetan for communication purpose. This may not apply to those attracted to Tibetan culture with a strong willingness to integrate themselves into Tibetan communities. Points discussed in 4.2 can also interfere with speakers' language competence. The weak role of Tibetan in the examination and higher education system, together with the lack of awareness towards the importance of non-standard varieties, could cause a loss of proficient second language speakers along with proficient native speakers.

When the trilingual education model was introduced in Tibet, the situation became even more complicated. Following the globalisation trend, more people have realised the necessity to learn the international lingua franca English. Xiao and Higgins implied that Tibetan students tend to try their best when learning Mandarin, but face difficulties when learning English. The interviewee in their research also highlighted that they thought English was useless in Tibet, and their class generally performed poorly in English examinations [24]. Teachers and students both struggled with English language education. Furthermore, little evidence can display that Tibetan people have enjoyed cognitive advantages of trilingual education [29]. On the contrary, cognitive, cultural and psychological problems occurred when ethnic minority groups in China tried to learn a third language [30]. While discussing with Tibetan university students, the author noted that the some of the students have lost confidence in learning languages or even learning other subjects if their performance in English is constantly poor. In this case, Tibetan students' willingness to learn English will be damaged, and they are less likely to learn and master the English language. The ecology of a trilingual environment in Tibet means Tibetan requires more effort to be maintained and promoted. The speakers' Tibetan language competence and tri-lingual ability have not shown the adequate capacity to improve the Tibetan language ecology.

\section{CONCLUSION}

This study used the first-grade indicators of "response" under Xiao and Fan's PSR model to look at the language ecology of Tibetan. Tibetan language's education, alongside people's attitudes towards the Tibetan language, and speakers' language competence have not sufficiently promoted Tibetan's language ecology. The education has not fundamentally changed Tibetan's vulnerable position. Although efforts have been made to protect the Tibetan language, Tibetan is still at risk of losing attraction to its speakers, and support tends to be given to Standard Tibetan language rather than other varieties. Speakers' language competence is in a complex situation as Tibetans are struggling under the trilingual education model. It is expected that this study could raise people's awareness of the language ecology of Tibetan as well as the RPS model developed by Chinese linguists. Tibetan is a critical language in China. While limited research has examined Tibetan from an ecolinguistic perspective, this brief study illustrated that Tibetan needs extensive attention and more effective support. The study can also indicate the situation of minority languages in China. Due to limited time and resources, and the author's inability to conduct a comprehensive field research in Tibet, this study used secondary and empirical data. It is recommended that more research, especially field research, be conducted on the ecological issues of Tibetan languages. It is worthwhile applying Xiao and Fan's PSR model to assess the ecology of a language systematically and comprehensively.

\section{ACKNOWLEDGMENT}

I acknowledge the support of Weiyuan Lake College and my Tibetan friends. I would like to thank Dr Wendy Jiang and Dr Guy Ramasay for their suggestions. I would like to thank Xiran Xiao and Rui Dang for helping me access a wider range of data. 


\section{REFERENCES}

[1] C. Moseley, Atlas of the world's languages in danger, 2010. http://www.unesco.org/languagesatlas/.

[2] G. Roche, The vitality of Tibet's minority languages in the twenty-first century: Preliminary marks, Multiethinia, vol. 35, 2014, pp. 18-24.

[3] G. Roche, Introduction: The transformation of Tibet's language ecology in the twenty-first century, International Journal of the Sociology of Language, 245, Berlin, 2017, pp. 1-35. DOI: 10.1515/ijsl-20170001

[4] G. Roche, L. Bum, Language revitalisation of Tibetan, Routledge Handbook of Language Revitalization, Routledge, New York, London, 2018, pp. 417-226.

[5] G. Roche, H, Suzuki, Tibet's minority languages: Diversity and Endangerment, Modern Asian Studies, 52(4), 2018, pp. 1227-1278. DOI: $10.1017 /$ S0026749X1600072X

[6] L. Zhang, L. Tsung, Zhuoma, Exploring sustainable multilingual language policy in minority higher education in China: A case study of the Tibetan Language, Sustainability, vol.12 (18), 2020, p. 7276. DOI: https://doi.org/10.3390/su12187267

[7] N. Tournadre, The Tibetic languages and their classification, in T. Owen-Smith and N. Hills (Eds.), Trans-Himalayan Linguistics, De Gruyter, Berlin, 2014, pp. 105-130.

[8] E. Haugen, The Ecology of Language, Stanford University Press, Stanford, 1972.

[9] N. Denison, 'A linguistic ecology for Europe?', Folia Linguistica, vol. 21(1-2), 1982, pp. 5-16. DOI: https://doi.org/10.1515/flin.1982.16.1-4.5

[10] M. Garner, Language ecoloy as linguistic theory, Kajian Linguistik dan Sastra, vol. 17(33), 2005, pp. 91-101. DOI: $10.23917 /$ kls.v17i2.4485

[11] M. A. K. Halliday, New ways of meaning: The challenge to applied linguistics, in A. Fill and P. Muhlhausler (Eds.), The Ecolinguistic Reader: Language, Ecology and Environment, Continuum, London, 2001, pp. 7-36 (Reprint of Halliday, 1990).

[12] R. Alexander, A. Stibbe, From and analysis of ecological discourse to the ecological analysis of discourse, Language Sciences, vol. 41, 2014, pp. 104-110. DOI: 10.1016/j.langsci.2013.08.011

[13] A. Stibbe, Ecolinguistics: Language, Ecology and the Stories We Live By, Routledge, Oxon, 2008.
[14] S. Chen, Language and ecology: A content analysis of ecolinguistics as an emerging research field, Ampersand, vol. 3, 2016, pp. 108-116.

[15] J. Wendel, P. Heinrich, A frame work for language endangerment dynamics: the effects of contact and social change on language ecologies and language diversity, International Journal of the Sociology of Language, vol. 218,2012, pp. 145-266.

[16] R. Posner, Language conflict in Romance: Decline, death and survival, in R. Posner and J. Green (Eds.), Bilingualism and Language Conflict in Romance, De Gruyter Mouton, Berlin, New York, 1993, pp. 41-76.

[17] United Nations, Pressure-state-response, n.d. https://www.unescwa.org/pressure-state-response

[18] Z. Xiao, J. Fan, Indicator system for measuring and assessing language ecology, Linguistic Sciences, vol. 10(3), 2011, pp. 270-280.

[19] Q. Pan, Investigation of English influence on Chinese language ecology: Taking Shanghai's as an example, Journal of Anhui Polytechnic University, vol. 31(6), 2016, pp. 80-85.

[20] C. Zou, A study on Chinese catchphrases from an ecolinguistics perspective, Doctoral dissertation, Central China Normal University, Wuhan, China.

[21] J. Zhang, Niche and market and individual practices in Tibetan language education in China: An ethnography of language policy, International Journal of Bilingual Education and Bilingualism, vol. 22(3), 2019, 274-289.

[22] R. Ma, Bilingual education and language policy in Tibet, in J. Leibold and Y. B. Chen (Eds.), Minority Education in China: Balancing Unity and Diversity in an Era of Critical Pluralism, Hong Kong University Press, Hong Kong, 2014, pp. 83-106.

[23] S. Ding, H. Liu, X. Li, Ethnic minority bilingual education in China, in Y. Li (Eds.), The Language Situation in China, vol. 1, De Gruyter Mouton/The Commercial Press, Berlin/Beijing, 2013, pp. 109122.

[24] Z. Xiao, S. Higgins, When English meets Chinese in Tibetan schools: Towards an understanding of multilingual education in Tibet, in A. Feng and B. Adamson (Eds.), Trilingualism in Education in China: Models and Challenges, Springer, Berlin, Heidelberg, 2015, pp. 117-140.

[25] X. Zhou, D. Jiang, Investigation of Tibetan language informationization and software use, in Y. Li (Eds.), The Language Situation in China, vol. 1, De Gruyter 
Mouton/The Commercial Press, Berlin/Beijing, 2013, pp. 213-220.

[26] Y. Ko, The sustainability of culture during times of economic development: A case study in Tibet, Master Thesis, HEC Paris, Paris, France.

[27] B. Adamson and A. Feng, Trilingualism in education: Models and Challengs, in A. Feng and B. Adamson (Eds.), Trilingualism in Education in China: Models and Challenges, Springer, Berlin, Heidelberg, 2015, pp. 243-258.

[28] J. Zhang, M. Pérez-Millans, Structures of feeling in language policy : The Case of Tibetan in China, Language Policy, vol. 18, 2019, pp. 39-64. DOI: https://doi.org/10.1007/s10993-018-9469-3

[29] F. Ma, Renzeng, Ethnolinguistic vitality, language attitudes and language education in Tibetan schools in Qinghai, in A. Feng and B. Adamson (Eds.), Trilingualism in Education in China: Models and Challenges, Springer, Berlin, Heidelberg, 2015, pp. 103-116.

[30] A. Feng, B. Adamson, Researching trilingualism and trilingual education in China, in in A. Feng and B. Adamson (Eds.), Trilingualism in Education in China: Models and Challenges, Springer, Berlin, Heidelberg, 2015, pp. 1-2. 